\title{
Investigation and analysis of standardized training for residents of general practitioners of Gansu Province in China
}

\author{
Hongjing Wang ${ }^{1 \dagger}$, Jin $\mathrm{He}^{1 \dagger}$, Dongzhi Zhang ${ }^{2 \dagger}$, Yue Wu${ }^{3}$, Peidong Wang ${ }^{4}$ and Hui Cai ${ }^{5,6^{*+}}$
}

\begin{abstract}
Background: China's standardized training for residents of General Practitioners (GPs) is aimed at providing the postgraduate training for family doctors who will serve the primary health care institutions. The aim of this paper is to investigate the standardized training situation, satisfaction with standardized training, work situation, intention, satisfaction and attitude of GPs who have finished standardized training.

Methods: This study was undertaken in 6 training hospitals in Gansu province using a questionnaire with 45 questions.

Results: Approximately 275 residents of GPs were enrolled. Finally, 263 residents completed the questionnaire (95.64\% response rate), including 133 females (50.57\%) and 130 males (49.43\%) with an average age of 28 years (standard deviation, 1.93 years; range, 25-36 years). Additionally, 56.65\% were single and $43.35 \%$ were married. Of all subjects, $92.40 \%$ residents had obtained certification of standardized training for residents of GPs and only $39.54 \%$ residents were satisfied with monthly income during training. There were 171 oriented rural medical graduates, of whom, only $42.69 \%$ expressed the willing to continue working in the primary health care institutions after the serve time (6 years) expired. Around $86.31 \%$ of residents of GPs who had finished standardized training got jobs with more than half serving in the primary health care institutions. For medical institutions and sanitary bureau were clear about general medicine policies, only 29.96\% subjects registered as GPs. Among the residents in general practice department, $68.42 \%$ were engaged in the diagnosis and treatment of common disease and frequentlyoccurring diseases as well as referral of patients. The percentage of residents who were satisfied with the job and income were 30.40 and $14.98 \%$, respectively.
\end{abstract}

Conclusion: Standardized training for residents of GPs in China is gradually improving. In order to cultivate more GPs and increase their willing to serve in the primary health care institutions, it is necessary to formulate and execute better policy of GPs, publize general medicine and improve the training quality.

Keywords: Standardized training, General practitioners, China

\footnotetext{
*Correspondence: caialon@163.com

${ }^{\dagger}$ Hongjing Wang, Jin He, Dongzhi Zhang and Hui Cai contributed equally to this work.

${ }^{5}$ Gansu Provincial Hospital, Lanzhou, Gansu, China

${ }^{6}$ Hospital Management Research Center, Lanzhou University, Lanzhou, Gansu, China

Full list of author information is available at the end of the article
}

(C) The Author(s). 2020 Open Access This article is licensed under a Creative Commons Attribution 4.0 International License, which permits use, sharing, adaptation, distribution and reproduction in any medium or format, as long as you give appropriate credit to the original author(s) and the source, provide a link to the Creative Commons licence, and indicate if changes were made. The images or other third party material in this article are included in the article's Creative Commons licence, unless indicated otherwise in a credit line to the material. If material is not included in the article's Creative Commons licence and your intended use is not permitted by statutory regulation or exceeds the permitted use, you will need to obtain permission directly from the copyright holder. To view a copy of this licence, visit http://creativecommons.org/licenses/by/4.0/ The Creative Commons Public Domain Dedication waiver (http://creativecommons.org/publicdomain/zero/1.0/) applies to the data made available in this article, unless otherwise stated in a credit line to the data. 


\section{Background}

China is a developing country with a population of more than 1.3 billion. With the development of society's economy and the improvement of the living level, people are demanding higher health care. At the same time, industrialization, urbanization and ecological environment changes more and more factors affecting health, population aging and changes in disease spectrum also put new demands on medical and health services. In the metropolis, difficulties in seeing a doctor and higher cost of seeing a doctor come from skip-level diagnosis and treatment. And this phenomenon stems from the weakness of the ability of primary medical institutions which leads to people's distrust of primary medical institutions. The construction of basic medical and health personnel team in China lags behind, and the number of qualified general practitioners (GPs) is insufficient, which restricts the improvement of basic medical and health services [1].

According to the 2018 China Statistical Yearbook, Gansu Province has 26,579 primary health care institutions, 199,155 health workers, and 21,358 rural health workers, lower than the average level in China (30,097, 378,673 and 31,331) [2]. The differential analysis on primary health care capacity showed regional differences among 31 regions in China with medical human resources of primary health care institutions in Gansu Province ranking at 16 [3]. In Gansu, the number of doctors per 1000 people is 2.26, below the average level in China (2.59). And the number of GPs per 10,000 people is only 2.58 , far from targeted number. So, qualified GPs of Gansu is inadequate.

A recent study from Stanford medical school and Harvard medical school proved that increasing primary care physicians resulted in decreased mortality. GPs are the main force of the medical team, and also the first doctor to visit when patients seek help for common diseases in American [4]. Barbara Starfield indicated that primary care contributed to prevent illness and death and primary care was associated with a more equitable health distribution among populations, and, therefore, health promoting value of primary care contributed a lot in health care system [5]. China has paid attention to primary care and the training and development of GPs. The standardized training system for residents has been tested in some provinces and cities, such as Sichuan, Shanhai and Beijing [6-8]. So far, this system is well implemented and resident physicians enjoy an improvement in clinical ability $[9,10]$. In Dec 2013, guidance on the establishment of standardized training system for residents was published by the National Health Commission of the People's Republic of China and other 7 departments. The standardized training system included 34 majors, including general medicine.
According to the guidance, all provinces will comprehensively launch standardized training for residents by 2015 , and a standardized training system for residents will be established by 2020. All medical clinicians with bachelor degree and above will receive standardized training for residents [11].

In China, GPs are called gatekeepers to the health of the inhabitants, who are comprehensive medical talents and undertake prevention, diagnosis and treatment of common and frequently-occurring diseases, referral, rehabilitation, chronic disease management and health management in the primary health care institutions. Therefore, the State Council issued opinions on the reform and improvement of cultivation and incentive mechanism for GPs [12]. Establishing a hierachical medical system and implementing a GP contract service, and the responsibility system for medical and health services to individual doctors are the development direction of China's medical and health services. By 2020, an energetic GP system will be established in China, and a unified and standardized GP training model, also the "firsttime in primary health care institutions" service model will be formed. The goal of two to three qualified GPs per 10,000 inhabitants in urban and rural areas will be achieved. The service level of GPs will be improved to requirements of the basic medical and health service needs of the people. However, there were only 253,000 qualified GPs in China and only 1.81 GPs per 10,000 populations by the end of 2017, far below the health needs of the people [13].

In 2010, the National Development and Reform Commission and other departments initiated the policy of free training for rural order-oriented medical students, in which, students could enjoy tuition-free education and subsistence allowance in the medical university. They should sign targeted employment agreements with the school, health commission and human resources society before getting admission notices and promise to serve in the rural primary health care institutions for 6 years after graduation. And they will be cultivated according to the GP requirements [14]. After reporting for duty, they participate in the three-year standardized training for residents of GPs, which is included in the six-year service period. During this period, they will be educated for general medicine primary knowledge, primary operational skills and especially dialectic thinking of clinical diagnosis and treatment. It includes 2 years and a half in hospital and 6 months in primary health care institutions with GP clinics. At present, the standardized training for rural order-oriented medical graduates is the main training method of GPs [15].

Since the implementation of the standardization training for GPs in Gansu Province in 2014, there have been two cohorts GP residents graduated. Therefore, it is 
necessary to investigate the training situation, work status and satisfaction to improve the training of GPs.

\section{Methods}

\section{Questionnaire formulation}

The questionnaire was discussed and formulated by experts including the administrative managers, clinical directors and clinical teachers in Gansu Provincial Hospital. A pilot-test was conducted in Gansu Provincial Hospital, and the questionnaire was evaluated for the reliability (Cronbach's alpha coefficient was 0.91 ) and validity (Goodness of Fit Index was 0.87). After the further modifications and revisions, the final questionnaire included 45 questions, concerning basic personal information (8 items), standardized training situation (9 items), satisfaction of standardized training (6 items), work situation and intention (13 items) and satisfaction of work and attitude for GPs (9 items).

\section{Sample size and method}

The research team reviewed all GPs who had finished standardized training in 6 training hospitals in 2017 and 2018, for the three-year standardized training for residents was fully initiated in 2014 in Gansu. Finally, 275 respondents met the requirements of the survey, and
273 completed questionnaires. Gansu Provincial Hospital was the quality control center for general medicine of Gansu, facilitating the investigation and research. A researcher was responsible for distributing the questionnaire and training hospitals directors and then collecting them. The study used an anonymous self-reporting method. All subjects provided written informed consents.

\section{Statistical analysis}

Invalid questionnaires were excluded and the data were analyzed in Excel with descriptive statistics (number and percentage).

\section{Results}

Basic characteristics

Approximately 275 residents of GPs were investigated. Finally, 263 residents were available (95.64\%) including $133(50.57 \%)$ women and $130(49.43 \%)$ men with an average age of 28 years with a $S D$ of 1.93 (Table 1). Of these subjects, $114(43.35 \%)$ were married and 149 (56.65\%) were single. There were $2(0.76 \%)$ with junior college degree, 240 (91.25\%) with bachelor degree and 21 (7.98\%) with master degree. The proportion of residents completing the standard training were $17.87 \%$

Table 1 Demographic characteristic of the respondents

\begin{tabular}{|c|c|c|c|}
\hline \multicolumn{2}{|l|}{ Demographic characteristic } & \multirow{2}{*}{$\begin{array}{l}\text { Frequency } \\
130\end{array}$} & \multirow{2}{*}{$\frac{\text { Percent }(\%)}{49.43}$} \\
\hline Gender & Male & & \\
\hline & Female & 133 & 50.57 \\
\hline \multirow[t]{3}{*}{ Age } & $<=25$ & 7 & 2.67 \\
\hline & $25-30$ & 223 & 84.79 \\
\hline & $>30$ & 33 & 12.54 \\
\hline \multirow[t]{2}{*}{ Marital status } & Married & 114 & 43.35 \\
\hline & Unmarried & 149 & 56.65 \\
\hline \multirow[t]{3}{*}{ Education } & Junior college degree & 2 & 0.76 \\
\hline & Bachelor degree & 240 & 91.25 \\
\hline & Master degree & 21 & 7.98 \\
\hline \multirow[t]{2}{*}{ Years of accepting training } & 2014-2017 & 47 & 17.87 \\
\hline & 2015-2018 & 216 & 82.13 \\
\hline \multirow[t]{6}{*}{ Residents of training hospital } & Gansu Provincial Hospital & 59 & 22.43 \\
\hline & The First Hospital of Lanzhou University & 96 & 36.50 \\
\hline & The Second Hospital of Lanzhou University & 57 & 21.67 \\
\hline & Chinese People's Liberation Army 940 Hospital & 41 & 15.59 \\
\hline & The First Hospital of Tianshui & 6 & 2.28 \\
\hline & The People's Hospital of Pingliang & 4 & 1.52 \\
\hline \multirow[t]{2}{*}{ Residents type } & Rural oriented medical graduates & 171 & 65.02 \\
\hline & Other graduates & 92 & 34.98 \\
\hline \multirow[t]{2}{*}{ Graduate type } & Fresh graduates & 224 & 85.17 \\
\hline & Former graduates & 39 & 14.83 \\
\hline
\end{tabular}


$(n=47)$ in 2017 and $82.13 \%(n=216)$ in 2018, respectively. Among all the 6 training hospitals, 59 (22.43\%) were trained in Gansu Provincial Hospital, 96 (36.50\%) in The First Hospital of Lanzhou University, 57 (21.67\%) in The Second Hospital of Lanzhou University, 41 (15.59\%) in Chinese People's Liberation Army 940 Hospital, 6 (2.28\%) in The First Hospital of Tianshui and 4 (1.52\%) in The People's Hospital of Pingliang. The study included 171 (65.02\%) rural oriented medical graduates. There were 224 (85.17\%) fresh graduates and 39 (14.83\%) former graduates.

\section{General situation of standardized training for residents of GPs}

A total of $243(92.40 \%)$ residents passed certification exam (Table 2), of whom, 180 (68.44\%) considered it necessary for the standardized training whereas 20 (7.60\%) thought it unnecessary. More than half of residents' monthly income was among 2000 and 3000RMB. Only 101(38.40\%) residents expressed improvement in the comprehensive ability by standardized training, while 77 (29.80\%) thought the training useless. The residents of GPs were improved mainly in clinical operational skills (91.63\%) and medical theoretical knowledge (71.48\%). Only 84 (31.94\%) residents of GPs deemed that their income were higher than other specialties. Of the rural oriented medical graduates, 73 (42.69\%) expressed the willing to continue to work in the primary health care institutions after the rural serve time was finished and more graduates $(57.31 \%)$ had no willing. Those who didn't want to work in the primary health care institutions planned to take part in the graduate candidate test $(69.39 \%)$ or find a better position $(74.49 \%)$.

\section{The satisfaction of residents of GPs on standardized training}

As shown in Table 3, 104 (39.54\%) residents were satisfied with monthly income, and other 55 (20.91\%) were unsatisfied, of whom, 30 (54.55\%) thought the satisfactory monthly income was between 3500 and 4000RMB. Among all the residents, more than half (62.74\%) were satisfied with teachers of standardized training, while 28 (10.64\%) were unsatisfied, of whom, 25 (89.29\%) were unsatisfied with teaching approach and 23 (82.14\%) teaching motivation. As for six-month community training, 98 (37.26\%) residents were satisfied and 76 (28.90\%) were unsatisfied, mainly due to the few patients $(69.74 \%)$ and the poor teaching motivation of teachers (59.21\%).

\section{Work situation and intention of GPs}

As shown in Table 4, 36 (13.69\%) had no jobs and 227 (86.31\%) residents had jobs after the standardized training, including 98(43.17\%) in hospitals and 129 (56.83\%) in primary medical and health institutions. Around 112
(59.34\%) residents received the monthly income between 3000 and 5000RMB and 95 (41.85\%) residents had lower income. Only 95 (41.85\%) medical institutions set up the general medical disciplines. Among those who had jobs, $9(3.96 \%)$ residents didn't pass the qualification of practicing medicine, $68(29.96 \%)$ residents were registered as GPs and $150(66.08 \%)$ were not registered for the following reasons:. "the medical institutions and sanitary bureau didn't know the general medicine policy and didn't agree" $(53.33 \%)$, "there was no difference in the detail work contents between GPs and other doctors" (32.67\%), "the diagnosis and treatment mode in the primary health care institutions was not suitable to the development of GPs" (28.00\%) and "the residents didn't want to register and liked to engage in specialized medical direction" (19.33\%) Most residents (107, 71.33\%) hoped that the range of practice medical license of GPs was expanded.

Around 134 (59.03\%) residents were assigned to the medical institution with only 19 (14.18\%) in the GP department for "diagnosis and treatment of common diseases and frequently-occurring diseases and the referral of patients" (68.42\%), "chronic disease management" (42.11\%) and "health management" (42.11\%), whereas the remaining 115 working in other departments such as internal, surgery, gynecology and pediatric departments. Of the remaining 115 residents, 50 (43.48\%) did the same work as those in GP departments and 62 (53.91\%) showed they wanted to be GPs.

\section{The job satisfaction of GPs and attitude of colleagues and local civilians to GPs}

As shown in Table 5, 69 (30.40\%) residents were satisfied with their job while $71(31.28 \%)$ were unsatisfied. Only 34 (14.98\%) residents were satisfied with their monthly income. Of the 102 residents unsatisfied with the income, 58 (56.86\%) showed the satisfactory monthly income was between 5000 and 6500RMB. Around 94 (41.41\%) indicated that their leaders put the construction of general medicine and cultivation of GPs in an important position. A low percentage (18.94\%) of residents showed their colleagues knew the standardized training for residents of GPs. Only 15 (6.61\%) residents thought that the local civilians knew the standardized training for residents of GPs in the primary health care institutions and only $39(17.18 \%)$ residents thought that the local civilians recognized residents of GPs who have finished the standardized training. The main reasons for being unfamiliar with residents of GPs included that "the local civilians had no idea to the standardized training for residents of GPs" (90.38\%), "the local civilians were used to visiting the familiar and experienced doctors" (78.85\%), "the local civilians thought residents of GPs were too young" (69.23\%) and "the local civilians 
Table 2 The situation of standardized training for residents of GPS

\begin{tabular}{|c|c|c|}
\hline Statements & Frequency & Percent (\%) \\
\hline \multicolumn{3}{|c|}{ Whether you obtain certification of the standardized training for residents of GPs. $(n=263)$} \\
\hline Yes & 243 & 92.40 \\
\hline No & 20 & 7.60 \\
\hline \multicolumn{3}{|c|}{ Is it necessary to launch the standardized training for residents of GPs. $(n=263)$} \\
\hline Necessary & 180 & 68.44 \\
\hline Neutral & 63 & 23.95 \\
\hline Non- necessary & 20 & 7.60 \\
\hline \multicolumn{3}{|c|}{ Monthly income during the standardized training for residents of GPs (RMB). $(n=263)$} \\
\hline$<=2000$ & 76 & 28.90 \\
\hline $2000-3000$ & 167 & 63.50 \\
\hline $3000-4000$ & 17 & 6.46 \\
\hline$>4000$ & 3 & 1.14 \\
\hline \multicolumn{3}{|c|}{ Is it useful to improve comprehensive ability of residents of GPs by standardized training. $(n=263)$} \\
\hline Yes & 101 & 38.40 \\
\hline A little & 85 & 32.32 \\
\hline No & 77 & 29.28 \\
\hline \multicolumn{3}{|c|}{ The abilities of residents of GPs are improved by standardized training. $(n=263)$} \\
\hline Medical ethics & 81 & 30.80 \\
\hline Medical theoretical knowledge & 188 & 71.48 \\
\hline Clinical operational skills & 241 & 91.63 \\
\hline Sociability & 129 & 49.05 \\
\hline Scientific research ability & 60 & 22.81 \\
\hline \multicolumn{3}{|c|}{ The income of GPs is higher than other specialties. $(n=263)$} \\
\hline Yes & 84 & 31.94 \\
\hline No & 179 & 68.06 \\
\hline
\end{tabular}

As a rural oriented medical graduate, whether you have the willing to continue to work in the primary health care institutions after the rural serve is finished. $(n=171)$

Yes

73

98

No

The reasons for not willing to continue to work in the primary health care institutions. $(n=98)$

The low income and fewer good policy or the policy is not been implemented

The limited career development

The poor primary medical environment

The imperfect general practice service mode

The wide range of specialties of general practice

The low support of primary health care institutions' leader for GPs

The main work is about public health but the clinic knowledge is less used

The big difference with schoolmates of other specialties

The plan of not continuing to work in the primary health care institutions. $(n=98)$

Take part in the graduate candidate test

Find a better position

Practice medicine individually

Change profession
42.69

57.31

84.69

89.80

67.35

79.59

31.63

32.65

32.65

15.31

69.39

74.49

21.43

27.55 
Table 3 The satisfaction of residents of GPs on standardized training

\begin{tabular}{|c|c|c|}
\hline Statements & Frequency & Percent (\%) \\
\hline \multicolumn{3}{|c|}{ The satisfaction of monthly income during the standardized training for residents of GPs. $(n=263)$} \\
\hline Satisfied & 104 & 39.54 \\
\hline Neutral & 104 & 39.54 \\
\hline Unsatisfied & 55 & 20.91 \\
\hline \multicolumn{3}{|l|}{ The satisfied monthly income (RMB) of residents of GPs. $(n=55)$} \\
\hline$<=3500$ & 5 & 9.09 \\
\hline $3500-4000$ & 30 & 54.55 \\
\hline $4000-4500$ & 14 & 25.45 \\
\hline$>4500$ & 6 & 1.81 \\
\hline \multicolumn{3}{|c|}{ The satisfaction of the teacher of standardized training for residents of GPs. $(n=263)$} \\
\hline Satisfied & 165 & 62.74 \\
\hline Neutral & 70 & 26.62 \\
\hline Unsatisfied & 28 & 10.64 \\
\hline \multicolumn{3}{|c|}{ The unsatisfied sides for the teacher of standardized training for residents of GPs. $(n=28)$} \\
\hline Medical ethics & 2 & 7.14 \\
\hline Clinical operational skill level & 20 & 71.43 \\
\hline Title of teacher & 18 & 64.29 \\
\hline Education of teacher & 15 & 53.57 \\
\hline Teaching motivation & 23 & 82.14 \\
\hline Teaching approach & 25 & 89.29 \\
\hline \multicolumn{3}{|l|}{ The satisfaction of the six-month community training. $(n=263)$} \\
\hline Satisfied & 98 & 37.26 \\
\hline Neutral & 89 & 33.84 \\
\hline Unsatisfied & 76 & 28.90 \\
\hline \multicolumn{3}{|c|}{ The unsatisfied sides for the six-month community training. $(n=76)$} \\
\hline The community training time is long & 35 & 46.05 \\
\hline The few patients in community & 53 & 69.74 \\
\hline The imperfect community equipments & 43 & 56.58 \\
\hline The insufficient community teachers & 37 & 48.68 \\
\hline The low ability of community teachers & 41 & 53.95 \\
\hline The poor teaching motivation of community teachers & 45 & 59.21 \\
\hline
\end{tabular}

didn't recognize the medical level of the primary health care institutions" (15.38\%). In order to increasing the recognition to residents of GPs who have finished the standardized training, $79.73 \%$ of residents thought that cultivation of GPs should be put in an important position and $78.85 \%$ considered that general medicine and GPs should be more publicized.

\section{Discussion}

The survey found that the overall qualified rate of standardized training for residents of GPs is high. Most residents believed that it was necessary to carry out standardized training for residents of GPs. At the same time, residents believed that their clinical ability and medical theory knowledge were improved through standardized training.

However, residents' satisfaction with training, job and income was low. Residents of GPs were not highly motivated by an internal drive, and especially for those married, the low income created a lot of stress in their life. Among the rural order-oriented medical graduates in 2017 and 2018, half expressed their reluctance to stay at the primary health care institutions after their service was finished, more than half said that they planned to take the graduate exam or find a better job, and even someone wanted to leave the medical position. They thought that, in the primary health care institutions, the income was low, most policies were poor, some good 
Table 4 Work situation and intention of GPS

\begin{tabular}{lc}
\hline Statements & Frequency \\
\hline Whether you have a job. & Percen \\
Yes & 227 \\
No & 36.31
\end{tabular}

The type of medical institutions. $(n=227)$

Hospital

Primary medical institutions

The hospital attributes. $(n=98)$

General hospital

Specialized hospital

Hospital of traditional Chinese and western medicine

The monthly income (RMB). $(n=227)$

$$
<=3000
$$

$3000-5000$

$5000-7000$

The medical institutions set up general medical discipline. $(n=227)$

Yes

No

Whether you are registered as a GP. $(n=227)$

Yes

No

Without qualification of practicing medicine

The reasons for not been registered as GPs. $(n=150)$

The residents do not want to register and like to engage in specialized medical direction

The medical institutions and sanitary bureau do not know the general medicine policy and do not agree

The diagnosis and treatment mode in the primary health care institutions is not suitable to the development of GPs

There is no difference in the detail work contents between GPs and other doctors

Whether you hope to expand the range of practice medical license of GPs. $(n=150)$

Yes

No

Whether you are assigned department in the medical institutions. $(n=227)$

Yes

No

The type of assigned departments. $(n=134)$

GP department

Internal department

Surgery department

Gynecology and pediatric department

Other departments

The routine work in the GP department. $(n=19)$

Prevention and healthcare

Diagnosis and treatment of common diseases and frequently-occurring diseases and the referral of patients

Patients' rehabilitation 
Table 4 Work situation and intention of GPs (Continued)

\begin{tabular}{|c|c|c|}
\hline Statements & Frequency & Percent (\%) \\
\hline Health management & 8 & 42.11 \\
\hline Other position & 7 & 36.84 \\
\hline \multicolumn{3}{|c|}{ The routine work of GPs are the same as other doctors. $(n=115)$} \\
\hline Yes & 50 & 43.48 \\
\hline No & 65 & 56.52 \\
\hline \multicolumn{3}{|c|}{ Whether you want to be GPs. $(n=115)$} \\
\hline Yes & 62 & 53.91 \\
\hline No & 53 & 46.09 \\
\hline
\end{tabular}

policy was not implemented well, the career development was limited and the GP service mode was imperfect.

Among the physicians who completed the standardized training of GPs, $13.68 \%$ had no jobs. More than half of the residents worked in the primary care institutions. It also found that only $41.85 \%$ of the institutions had general medical or general outpatient clinics, and only $29.96 \%$ of the residents were registered as GPs in their institutions. There are some reasons why residents are not registered as GPs: "local institution and the health bureau did not know the specific policies of the GP", "the current working scope of the GPs was the same as other professional residents", and "some residents want to engage in specialist medical care".

Only $18.94 \%$ of residents believed that their colleagues understood the standardized training for residents of GPs, and more than half of the residents believed that the institution did not pay attention to the construction of general medicine and the training of GPs. The residents' overall satisfaction with the current work and the current job income were not high. Residents expressed that local people did not understand the standardization training for residents of GPs for they were accustomed to visiting familiar and experienced doctors and these residents were too young to be trusted for the service capabilities of primary care units.

In Gansu Province, few studies have examined the effectiveness of standardization training for residents of GPs. One study indicated that the current primary health care doctors were poor in knowledge and service capabilities, and in order to achieve the desired objective, bold reforms in the primary health care system should be carried out in the primary health care system and the welfare of primary health care doctors should be substantially improved [16]. Some studies indicated that the only ways to implement graded medical care and the key to promote primary health care were strengthening the standardized training and assessment of GPs and improving the service capacity of primary medical institutions [17-19]. Moreover, to ensure the quality of training and improve residents' motivation and self-regulation abilities, self-directed learning (SDL) should be advocated, faculty development programs should be organized, and strong academic basis and evidence-based guidelines should be developed [20]. It is well-known that the doctors with the excellent clinical ability do not necessarily teach students well, and therefore, it is necessary to improve the teaching level of teachers, especially the training methods. One study showed it very useful to explore the applications of the instructor-based teaching method in training [21]. GPs mainly served in the primary health care institution after 3 years of training. Hence, one-sixth of the training should be implanted in the community. However, some residents may have gained experience as a junior doctor or transferable work experience beyond the medical field before. Thus, trainees differ in competencies prior to residency resulting in a different training period [20]. Literatures also suggested efforts in exploring the collaborative co-construction model of the standardized training for residents of GPs in the clinical and community bases [22]. Comparing with the primary care systems in Brazil, universal care, human rights, social justice and health equity should also be emphasized during the standardized training [23].

According to response of Ministry of Education of the People's Republic of China to recommendation no. 5382 of the second session of the 13th National People's Congress, general practice medical education and clinical practice was claimed for all medical undergraduates. From the perspective of international experience and the growth law of medical talents, the undergraduate education of medical colleges and universities generally sets up clinical medicine specialty, so as to lay a solid and generous medical foundation for clinical medical students. The training of GPs is mainly completed after graduation, such as standardized training of resident physicians [24]. Even in the UK with its relatively wellestablished model of general practice, there is still bias in medical schools towards hospital medical careers. Depending on the foreign experience, there is urgent need to develop and promote awareness and understanding of general practice for medical undergraduates, improve 
Table 5 The job satisfaction of GPs and attitude of colleagues and local civilians to GPS

\begin{tabular}{|c|c|c|}
\hline Statements & Frequency & Percent (\%) \\
\hline \multicolumn{3}{|l|}{ The satisfaction of the work. $(n=227)$} \\
\hline Satisfied & 69 & 30.40 \\
\hline Neutral & 87 & 38.33 \\
\hline Unsatisfied & 71 & 31.28 \\
\hline \multicolumn{3}{|l|}{ The satisfaction of the monthly income. $(n=227)$} \\
\hline Satisfied & 34 & 14.98 \\
\hline Neutral & 91 & 40.09 \\
\hline Unsatisfied & 102 & 44.93 \\
\hline \multicolumn{3}{|l|}{ The satisfied monthly income (RMB). $(n=102)$} \\
\hline$<=5000$ & 15 & 14.71 \\
\hline $5000-6500$ & 58 & 56.86 \\
\hline $6500-8000$ & 23 & 22.55 \\
\hline$>8000$ & 6 & 5.88 \\
\hline \multicolumn{3}{|c|}{ The leaders put the construction of general medicine and cultivation of GPs in an important position. $(n=227)$} \\
\hline Yes & 94 & 41.41 \\
\hline No & 133 & 58.59 \\
\hline \multicolumn{3}{|l|}{ The awareness of colleagues for the standardized training for residents of GPs. $(n=227)$} \\
\hline Yes & 43 & 18.94 \\
\hline Neutral & 90 & 39.65 \\
\hline No & 94 & 41.41 \\
\hline \multicolumn{3}{|c|}{ The awareness of local civilians for the standardized training for residents of GPs in the primary health care institutions. $(n=227)$} \\
\hline Yes & 15 & 6.61 \\
\hline No & 212 & 93.39 \\
\hline \multicolumn{3}{|c|}{ The recognition of local civilians to residents of GPs who have finished the standardized training. $(n=227)$} \\
\hline Yes & 39 & 17.18 \\
\hline Neutral & 136 & 59.91 \\
\hline No & 52 & 22.91 \\
\hline \multicolumn{3}{|c|}{ The reasons for being unfamiliar with residents of GPs who have finished the standardized training. $(n=52)$} \\
\hline Residents of GPs are too young & 36 & 69.23 \\
\hline The local civilians are used to visiting the familiar and experienced doctors & 41 & 78.85 \\
\hline The local civilians have no idea to the standardized training for residents of GPs & 47 & 90.38 \\
\hline The local civilians don't recognize the medical level of the primary health care institutions & 8 & 15.38 \\
\hline \multicolumn{3}{|c|}{ Measures to increase recognition to residents of GPs who have finished the standardized training. $(n=227)$} \\
\hline The cultivation of GPs should be put in an important position & 181 & 79.73 \\
\hline The health education lecture and the free diagnosis activities should be carried out & 133 & 58.59 \\
\hline To increase contract services for family doctors & 120 & 52.86 \\
\hline To increase publicity of general medicine and GPs & 179 & 78.85 \\
\hline To increase construction of primary medical units and the quality of manager & 35 & 15.42 \\
\hline
\end{tabular}

access to the quality of work experience in general practice for prospective medical students, and strengthen collaboration to raise the academic profile and future vision of general practice and tackle the tensions which surround general practice [25]. This will take a long time and must start as early as possible in medical training.

\section{Strengths and limitations}

The standardized training for residents was initiated in 2014 In Gansu, China, this current study investigated the training situation, working situation and satisfaction of resident of GPs who have finished standardized training for the first time. There are some limitations in the 
current study that should be addressed. First, the survey was conducted soon after the first two cohorts residents of GPs graduated from standardized training, and therefore, the satisfaction was low. Presently, satisfaction should be increased over years of working in gathering the experience and improving the better treatment. The further survey will be carried out around 3 years later. In addition, in the study, there was no special survey on primary medical workers and local civilians for GPs and related policy, so the understanding of primary medical workers and local civilians for GPs and related policy was not accurate.

\section{Conclusions}

The satisfaction for standardized training of GP residents with regard to job and income was low in Gansu. The diagnosis and treatment model in current primary care institutions is in a transitional stage in China and the standardized training for residents of GPs is increasingly improved. So the current study provides evidence and decision-making basis for cultivation of GPs. The better policies for GPs should be further formulated and executed, concerning the income of GPs, attractiveness to GPs, the publicity of standardized training, the training quality and the construction of primary medical institutions. And also the local government should make efforts to solve the employment of GPs madding them play an important roles in the primary health care.

\section{Abbreviations}

GPS: General Practitioners; GP: General Practice; SDL: Self-directed learning

\section{Acknowledgements}

We thank Ruiyuan Yi and Fei Yu (Health Commission of Gansu Province) for providing the survey support throughout this study and Xiaoli Li (Nephrology department of Gansu Provincial Hospital) for assistance in the language revision of manuscript.

\section{Authors' contributions}

Conceived and designed the survey: HC. Performed the survey: HJW, JH, DZZ, YW, PDW. Analyzed the data: HJW, JH, DZZ. Contributed materials/ analysis tools: HJW, JH, DZZ. Wrote the paper: HJW, JH, DZZ. All authors have read and approved the final manuscript.

\section{Funding}

This work was supported by scientific research foundation of Gansu Provincial Hospital (17GSSY9-4), HJW received the funding. The funder had no role in study design, data collection and analysis, decision to publish, or reparation of the manuscript.

\section{Availability of data and materials}

The data that support the findings of this study are not publicly available because they contain information that could compromise research participant privacy. Under certain circumstances, the data may be available from the corresponding author on reasonable request.

\section{Ethics approval and consent to participate}

All participants were provided with a plain language statement explaining the study and gave written informed consent in the questionnaire survey. The study was approved by Ethics approval for scientific research of Gansu Provincial Hospital (2018-148).
Consent for publication

Not applicable.

\section{Competing interests}

The authors declare that they have no competing interests.

\section{Author details}

'Department of Medical Affairs, Gansu Provincial Hospital, Lanzhou, Gansu, China. ${ }^{2}$ Department of Discipline Construction Management, Gansu Provincial Hospital, Lanzhou, Gansu, China. ${ }^{3}$ Department of Burn, Gansu Provincial Hospital, Lanzhou, Gansu, China. ${ }^{4}$ Department of Residents Training Management, Gansu Provincial Hospital, Lanzhou, Gansu, China. ${ }^{5}$ Gansu Provincial Hospital, Lanzhou, Gansu, China. ${ }^{6}$ Hospital Management Research Center, Lanzhou University, Lanzhou, Gansu, China.

Received: 23 July 2019 Accepted: 9 June 2020

Published online: 19 June 2020

\section{References}

1. The State Council. Guidelines for the establishment of the general practitioner system. 2011. Available: http://www.gov.cn/zwgk/2011-07/07/ content_1901099.htm.

2. National Bureau of Statistics of China. China statistical yearbook of 2018. Beijing: China Statistics Press; 2018. Available: http://www.stats.gov.cn/tjsj/ ndsj/2018/indexch.htm.

3. Zhang YQ, Wang GL. Analysis on the differences of service capability of primary health care institutions in China based on entropy-topsis method. Chineses Health Serv Manag. 2018;7:509-12 Chinese.

4. Basu S, Berkowitz SA, Phillips RL, Bitton A, Landon BE, Phillips RS. Association of primary care physician supply with population mortality in the United States, 2005-2015. JAMA Int Med. 2019. https://doi.org/10.1001/ jamainternmed.2018.7624.

5. Starfield B, Shi L, Macinko J. Contribution of primary care to health systems and health. Milbank Q. 2005;83(3):457-502.

6. Shi JF, Gong Y, Li F, Cai L, Li YF. Innovation and practice in standardized training management for residents in a base hospital. Shi Yong Yi Yuan Lin Chuang Za Zhi. 2013;10(3):193-5 Chinese.

7. Chen C, Tian DJ, Luo Q, Tan J, Zhang Q. Application of systematic management on faculty doctors in standardized residents training. Chin J Educ. 2013;33(1):144-7 Chinese.

8. Ding J, Wei B, Du XP. Teaching experiences in standardized rotation of general practitioner residency in community health service centers. Chin Gen Pract. 2011;14(10A):3295-6 Chinese.

9. Tang M, Liu WB, Zhao LB, Wang JY, Chen YY. Preliminary evaluation of training effect of the standardized training program for resident physicians in Shanghai. Chin Health Resour. 2013;16(2):106-8 Chinese.

10. Zhu B, Chen M, Sun GH. Quality management in the standardized residents training. China J Med Educ. 2009;29(4):134-6 Chinese.

11. The National Health Commission of the People's Republic of China. Guidance on the establishment of standardized training system for residents. 2013. Available: http://www.nhfpc.gov.cn/qjjys/s3593/201401/032 c8cdf2eb64a369cca4f9b76e8b059.shtml.

12. The State Council. Opinions on the reform and improvement of the training and use of incentive mechanism for general practitioners. 2018. Available: http://www.gov.cn/zhengce/content/2018-01/24/content_5260073.htm.

13. The National Health Commission of the People's Republic of China. Letter on the reply to proposition 2516 of the first session of the 13th national committee of the Chinese people's political consultative conference. 2019. Available: http://www.nhc.gov.cn/wjw/tia/201901/860694646e61487eb6ee4 e8551b3c177.shtml.

14. National Development and Reform Commission, Ministry of Health, Ministry of Education, Ministry of Finance, Ministry of Human Resources and Social Security. The notice of the issuance and distribution of rural order oriented medical students free of charge training work implementation. 2010. Available: http://www.gov.cn/zwgk/2010-06/08/content_1623025.htm.

15. The ministry of education and other six departments in China. The free training advice of further rural order-oriented medical students. 2015. Available: http://www.moe.gov.cn/srcsite/A08/moe_740/s7955/201505/t2015 0520_189494.html.

16. Zheng L. Improving the primary doctors' medical service capacity was the key to promote hierarchical diagnosis system. Chin Gen Pract. 2016;35(9):67-9 Chinese. 
17. Jiang $\mathrm{CL}$, Fu JH, Li YC. Exploring the system roots of service capacity weakening in Chinese primary medical institutions. Chin Health Econ. 2018; 37(10):54-7 Chinese.

18. Liu LQ. Improving capacities of health services delivery: the key to the sustainable development of primary medical service system. Chin Gen Pract. 2017;20(4):379-82 Chinese.

19. Akdeniz M, Yaman H, Akbayn Z, et al. Family practice in Turkey: views of family practice residents. Postgrad Med. 2011;123(3):144-9.

20. de Sarah B, Jettie B, Nynke S. Strengthening general practice by extending specialty training? Br J Gen Pract. 2019;69:222-3.

21. Shi P, He YN. Application of supervisor responsibility system in standardized training for residency of general practitioners. Basic Clin Med. 2013;33(10): 1360-2 Chinese.

22. Shi DD, Zhou R, Shen FL, Zhang K. Joint efforts of clinical medicine and community centers in standardized residency training in Shanghai. Chin J Hosp Adm. 2015;10:897-9 Chinese.

23. Cubaka VK, Dyck C, Dawe R, et al. A global picture of family medicine: the view from a WONCA Storybooth. BMC Fam Pract. 2019;20:129.

24. Ministry of Education of the People's Republic of China. Response to recommendation no. 5382 of the second session of the 13th National People's Congress. 2019. Available: http://www.moe.gov.cn/jyb_xxgk/xxgk_ jyta/jyta_gaojiaosi/201911/t20191120_409018.html.

25. Health Education England. By choice-not by chance: supporting medical students towards careers in general practice. 2016. Available: https://www.hee nhs.uk/our-work/supporting-medical-students-towards-careers-general-practice.

\section{Publisher's Note}

Springer Nature remains neutral with regard to jurisdictional claims in published maps and institutional affiliations.

Ready to submit your research? Choose BMC and benefit from:

- fast, convenient online submission

- thorough peer review by experienced researchers in your field

- rapid publication on acceptance

- support for research data, including large and complex data types

- gold Open Access which fosters wider collaboration and increased citations

- maximum visibility for your research: over $100 \mathrm{M}$ website views per year

At $\mathrm{BMC}$, research is always in progress.

Learn more biomedcentral.com/submissions 